Wayne State University

DigitalCommons@WayneState

Psychology Faculty Research Publications

Psychology

6-1-2013

\title{
Duel or Diversion? Conscientiousness and Executive Function in the Prediction of Health and Longevity
}

Tim Bogg

Wayne State University, tdbogg@gmail.com

Brent W. Roberts

University of Illinois at Urbana-Champaign

\section{Recommended Citation}

Bogg T. and Roberts B. W. (2013). Duel or diversion? Conscientiousness and executive function in the prediction of health and longevity. Annals of Behavioral Medicine 45(3): 400-401. DOI: 10.1007/s12160-013-9468-8

Available at: http://digitalcommons.wayne.edu/psychfrp/18

This Response or Comment is brought to you for free and open access by the Psychology at DigitalCommons@WayneState. It has been accepted for inclusion in Psychology Faculty Research Publications by an authorized administrator of DigitalCommons@WayneState. 
NOTICE IN COMPLIANCE WITH PUBLISHER POLICY: This is the author's final accepted manuscript version ('post-print'), formatted for archiving; a definitive version was subsequently published in Annals of Behavioral Medicine 45(3): 400-401. (June 2013). The final publication is available at link.springer.com: http://dx.doi.org/10.1007/s12160-013-9468-8 


\section{Duel or Diversion? Conscientiousness and Executive Function in the Pre- diction of Health and Longevity}

TIM BOGG, Department of Psychology, Wayne State University, Detroit, MI 48202

BRENT W. ROBERTS, Department of Psychology, University of Illinois at Urbana-Champaign, Champaign, IL 61820

Corresponding author

TIM BOGG email:tdbogg@gmail.com tel:313-577-2836 fax:313-577-7636

In their letter to the editor, Hall and Fong (this issue) present post hoc analyses to support their contention that executive function is a more potent predictor of two health-related behaviors than the personality trait domain of conscientiousness. These analyses, along with an outdated critique of personality traits, lead them to conclude that conscientiousness requires a "careful re-construction...from a social neuroscience perspective". We see no reason to do so, for three reasons: 1) executive functioning currently lacks appropriate levels of construct validity; 2) findings from our own research fail to support the authors' contention; and 3) the social cognitive models of traits implied by the authors are common and have been examined for more than a decade.

The authors seem to suggest that executive functioning is worthy of greater research attention than conscientiousness. While we cannot deny that such concepts have received ample research attention, meta-analyses of measures related to executive functioning produce low convergent correlations (1). Before conscientiousness can be supplanted by alternative constructs like executive functioning, it is necessary for researchers to provide more compelling evidence of their coherence and validity.

Second, although we accept the veracity of Hall and Fong's findings, we conducted a highly similar study that included a wider variety of executive functioning measures and multiple methods for assessing conscientiousness (2). The results showed there to be few associations between executive function outcomes and conscientiousness-related traits, indicating little overlap between these putative markers of impulse control. Moreover, regression analyses showed there to be independent predictions from self-control facets of conscientiousness (including observer reports) and Go-NoGo task performance to measures of wellness maintenance, accident control, and substance risk.

Third, the authors argue for a social neuroscience reconceptualization of conscientiousness. We take this to mean that conscientiousness should be a hierarchical, social cognitive construct. At the lower level of such a structure would be cognitive capacities akin to executive functioning. Given its current operationalizations, we are skeptical executive functioning would suffice. Moreover, integrative models of this sort were proposed as early as 2001 (3), and continue to be a focus of theoretical and conceptual attention, especially in personality psychology $(4,5)$.

The analyses of Hall and Fong highlight two of the points of emphasis from our review: 1) The identification of mediating and moderating factors of conscientiousness-health relations is a key task; and 2) Facets matter when examining relations between conscientiousness and health outcomes. Among the limitations of the authors' winner-takes-all "competitive test" is the inability to examine direct and indirect effects. Might executive function mediate the relationship between conscientiousness and the diet/physical activity outcomes or, alternatively, would stronger effects be found if a measure of industriousness were used - a conscientiousness-related facet which has shown more robust relations to diet/physical activity than global measures of conscientiousness (6)?

In closing, we would be remiss if we did not address the authors' characterization of conscientiousness-health relations as errant byproducts of cross-sectional mono-method (i.e., self-report) designs. Related issues have been covered ad nauseum elsewhere $(7,8)$, but we feel credit is 
due to those researchers whose multi-source and/or longitudinal designs resulted in many of the important findings discussed in our review. There are few more parsimonious accounts of the power of personality than showing how parent and teacher ratings of childhood conscientiousness predict longevity $(9,10)$. In comparison, there is a paucity of research showing the longterm health effects of constructs related to executive functioning.

Executive function likely plays a role in health and longevity, but the evidence does not support the reformulation of conscientiousness as a logical corollary to such an assertion.

\section{REFERENCES}

1. Duckworth AL, Kern ML. A meta-analysis of the convergent validity of self-control measures. $J$ Res Pers. 2011; 45: 259-268.

2. Edmonds GW, Bogg T, Roberts BW. Are personality and behavioral measures of impulse control convergent or distinct predictors of health behaviors? J Res Pers. 2009; 43: 806-814.

3. Fleeson W. Toward a structure- and processintegrated view of personality: Traits as density distributions of states. J Pers Soc Psychol. 2001; 80: 1011-1027.
4. Fleeson W, Noftle EE. Where does personality have its influence? A supermatrix of consistency concepts. J Pers. 2008; 76: 1355-1386.

5. Cramer AOJ et al. Dimensions of normal personality as networks in search of equilibrium: You can't like parties if you don't like people. Euro $J$ Pers. 2012; 26: 414-431.

6. Bogg T, Roberts BW. Conscientiousness and health-related behaviors: a meta-analysis of the leading behavioral contributors to mortality. Psychol Bull. 2004; 130: 887-919.

7. Kenrick DT, Funder DC. Profiting from controversy: Lessons from the person-situation debate. Am Psychol. 1988; 43: 23-34.

8. Roberts BW, Caspi A. Personality development and the person-situation debate: It's déjà vu all over again. Psychol Inquiry. 2001; 12: 104-109.

9. Friedman HS, Tucker JS, Tomlinson-Keasey C, et al. Does childhood personality predict longevity? J Pers Soc Psychol. 1993; 65: 176-185.

10. Deary, IJ, Batty GD, Pattie A, Gale CR. More intelligent, more dependable children live longer. Psychol Sci. 2008; 19: 874-880. 